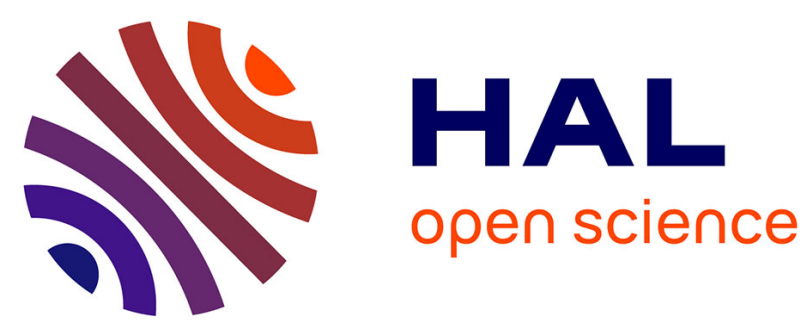

\title{
Porous Organic Polymers Containing Active Metal Centers for Suzuki-Miyaura Heterocoupling Reactions
}

Noelia Esteban, María Ferrer, Conchi Maria Concepcion Ovin Ania, José de La Campa, Ángel Lozano, Cristina Álvarez, Jesús Miguel

\section{- To cite this version:}

Noelia Esteban, María Ferrer, Conchi Maria Concepcion Ovin Ania, José de La Campa, Ángel Lozano, et al.. Porous Organic Polymers Containing Active Metal Centers for Suzuki-Miyaura Heterocoupling Reactions. ACS Applied Materials \& Interfaces, 2020, 12 (51), pp.56974-56986. 10.1021/acsami.0c16184 . hal-03433532

\section{HAL Id: hal-03433532 https://hal.science/hal-03433532}

Submitted on 18 Nov 2021

HAL is a multi-disciplinary open access archive for the deposit and dissemination of scientific research documents, whether they are published or not. The documents may come from teaching and research institutions in France or abroad, or from public or private research centers.
L'archive ouverte pluridisciplinaire HAL, est destinée au dépôt et à la diffusion de documents scientifiques de niveau recherche, publiés ou non, émanant des établissements d'enseignement et de recherche français ou étrangers, des laboratoires publics ou privés. 


\section{Porous Organic Polymers Containing Active Metal \\ Centers for Suzuki-Miyaura heterocoupling}

\section{reactions}

Noelia Esteban ${ }^{1}$, María L. Ferrer ${ }^{2}$, Conchi O. Ania ${ }^{3}$, José G. de la Campa ${ }^{4}$, Ángel E. Lozano ${ }^{1,4,5}$,

Cristina Álvarez ${ }^{4,5 *}$, Jesús A. Miguel ${ }^{1}$.

1. IU CINQUIMA, Univ. de Valladolid, Paseo Belén 5, E-47011 Valladolid, Spain.

2. Materials Science Factory, Instituto de Ciencia de Materiales de Madrid, CMM-CSIC, Campus de Cantoblanco, 28049 Madrid, Spain.

3. CEMHTI CNRS (UPR 3079), University of Orléans, 45071 Orléans, France.

4. Instituto de Ciencia y Tecnología de Polímeros, ICTP-CSIC, Juan de la Cierva 3, E-28006 Madrid, Spain.

5. SMAP, UA-UVA_CSIC, Associated Research Unit to CSIC. Universidad de Valladolid, Facultad de Ciencias, Paseo Belén 7, E-47011 Valladolid, Spain.

KEYWORDS: Porous organic polymers, bipyridine, Suzuki-Miyaura reaction, Pd catalyst, confined catalyst. 


\section{ABSTRACT}

A new generation of confined palladium(II) catalysts covalently attached inside of porous organic polymers (POPs) has been attained. The synthetic approach employed was straightforward, and no prerequisite of making any modification of the precursor polymer was needed. First off, POP-based catalytic supports were obtained by reacting one symmetric trifunctional aromatic monomer (1,3,5-triphenylbenzene) with two ketones having electronwithdrawing groups (4,5-diazafluoren-9-one, DAFO, and isatin) in superacidic media. The homopolymers and copolymers were made using stoichiometric ratios between the functional groups and they were obtained with quantitative yields after an optimization of reaction conditions. Moreover, the number of chelating groups (bipyridine moieties) available to bind $\operatorname{Pd}(\mathrm{II})$ ions in the catalyst supports was modified using different DAFO/isatin ratios. The resulting amorphous polymers and copolymers showed high thermal stability, above $500{ }^{\circ} \mathrm{C}$, and moderate-high specific surface areas (from 760 to $935 \mathrm{~m}^{2} \mathrm{~g}^{-1}$ ), with a high microporosity contribution (from $64 \%$ to $77 \%$ ). Next, POP-supported Pd(II) catalyst were obtained by simple immersion of the catalyst supports in a palladium (II) acetate solution, observing that the metal content was similar to that theoretically expected according to the amount of the bipyridine groups. The catalytic activity of these heterogeneous catalysts was explored for the synthesis of biphenyl and terphenyl compounds, via the Suzuki-Miyaura cross-coupling reaction using a green solvent (ethanol/water), low palladium loads and aerobic conditions. The findings showed excellent catalytic activity with quantitative product yields. Additionally, the recyclability of the catalysts was excellent because after 5 cycles of use, by a simple washing with ethanol, the coupling yield was higher than $95 \%$. Finally, the feasibility of these catalysts to be employed in tangible organic reactions was assessed. Thus, the synthesis of a bulky compound, 4-4"- 
dimetoxi-5'-t-butyl-m-terphenylene, which is a precursor of a thermally rearrangement monomer, was scaled-up to $2 \mathrm{~g}$, with high conversion and $96 \%$ yield of pure product.

\section{INTRODUCTION}

Suzuki-Miyaura cross-coupling reaction between haloderivatives and boronic acids catalyzed by $\operatorname{Pd}(0)$ compounds, which was awarded with the Nobel Laureate in $2010,{ }^{1,2}$ is one of the most reliable, efficient and practical methodologies for the formation of $\mathrm{C}-\mathrm{C}$ bonds since its first reports in $1979 . .^{2-6}$ In particular, the reaction is a versatile and powerful methodology, for example, in the construction of biaryl compounds and the substitution and modification of aromatic and heteroaromatic moieties. ${ }^{6-8}$ In this context, the Suzuki-Miyaura reaction is used in many research fields because it permits the efficient discovery, development and synthesis of pharmaceutical and chemical compounds, of different kinds of engineering materials (liquid crystals, polymers, molecular wires, etc.), coordination chemistry materials, supramolecular chemistry, and diverse functional materials. ${ }^{1,8-12}$

Nowadays, one of the main concerns in scientific research, especially for pharmaceutical and chemical industries, is the search for greener, safer, environmentally friendly and efficient technologies. ${ }^{13,14}$ Specifically, the use of recyclable heterogeneous catalysts for organic synthesis allows for the reduction of waste production and the optimization of the efficiency of the synthetic process, and therefore research in this area is of utmost importance.

Porous organic polymers, POPs, have shown great efficiency as new catalyst supports in heterogeneous catalysis, thanks to properties such as high microporosity and the possibility of incorporating high catalyst loads. ${ }^{12,15}$ In particular, the inclusion of metal catalysts confined in microporous cavities has given rise to materials having excellent turnover number, TON, and turnover frequency, TOF, high regioselectivities, high recyclability and low metal contamination 
of the obtained products. It has been demonstrated that the confinement of catalyst produces a variation in the energetic and kinetic properties of the catalytic process, which improves its yield and selectivity.

The development of new POP materials with high thermal stability and high specific surface area is booming for advanced applications such as $\mathrm{CO}_{2}$ capture, gas separation and storage, sensor preparation or heterogeneous catalysts. ${ }^{16-21}$ These POP materials can be manufactured using a variety of different methodologies to achieve tailored properties. Olah et al. proposed the activation of electrophiles in Brønsted or Lewis super acidic media in order to obtain reactants that show a significantly higher electrophilic character. ${ }^{22-25}$ Following Olah's methodology, Zolotukhin et al. obtained linear polymers by using a one-pot SEAr reaction of ketones having electron-withdrawing groups (for instance, isatin or trifluoroacetophenone) with diaromatic hydrocarbons (for instance, biphenyl or p-terphenyl). These linear polymers showed high molecular weight and exhibited good chemical and thermal stability (around $500{ }^{\circ} \mathrm{C}$ ). Furthermore, these polymers could be employed as gas separation membranes, which showed excellent values of permeability and selectivity. ${ }^{26-29}$

Recently, in our research group, a new generation of porous polymer network were synthesized following Olah's methodology, by reaction of ketones having electron-withdrawing groups (i.e.; isatin and trifluoroacetophenone) with rigid trifunctional aromatic monomers (triptycene and 1,3,5-triphenylbenzene) employing triflic acid as a superacidic media. ${ }^{30}$ These polymers showed high surface areas between 580 and $790 \mathrm{~m}^{2} \mathrm{~g}^{-1}$, high thermal stability and excellent $\mathrm{CO}_{2}$ uptakes and were employed as fillers to prepare mixed matrix membranes displaying excellent gas separation performances. ${ }^{21}$ 
Following this research line, we have now introduced a set of microporous polymer networks, POPs, having a rigid bipyridine moiety in its structure. These POPs were able to efficiently form confined Pd catalysts by simple immersion in a Pd(II) acetate solution. The catalysts thus obtained have been evaluated for the Suzuki-Miyaura reaction of a wide variety of haloaromatic derivatives and boronic acids with high yields and TOF and TON values.

\section{EXPERIMENTAL PART}

\subsection{Materials}

All reagents were purchased and used without any purification except 4,5-diazafluoren-9-one (DAFO), which was synthesized in our laboratory following the methodology described elsewhere. $^{31,32}$ The detailed synthesis of DAFO is described in the supporting Information section (SI).

\subsection{Techniques}

Fourier Transform Infrared (FTIR-ATR) spectra were recorded on a PerkinElmer Spectrum RX-I FT-IR spectrometer, equipped with an attenuated total reflection accessory (ATR) Pike Gladi ATR-210. Solid-state ${ }^{13} \mathrm{C}$ cross-polarization magic angle spinning NMR spectra (CP/MAS ${ }^{13} \mathrm{C}$ NMR) spectra were recorded on a Bruker Avance TM 400WB spectrometer, equipped with a $89 \mathrm{~nm}$ wide-bore and a $9.4 \mathrm{~T}$ superconducting magnet, operating at frequency of $100.6 \mathrm{MHz}$, using $1 \mathrm{~ms}$ contact pulses, a delay time of $3 \mathrm{~s}$ and a rotation rate of $11 \mathrm{kHz}$. Dynamic thermogravimetric analysis (TGA) were performed on a TA-Q500 instrument under a continuous nitrogen flow $\left(60 \mathrm{~mL} \mathrm{~min}^{-1}\right)$, operating with a Hi-Res method at a heating rate of $20{ }^{\circ} \mathrm{C} \mathrm{min}^{-1}$ and sensitivity and resolution parameters of 1 and 4, respectively. Wide-Angle X-ray Scattering (WAXS) patterns were recorded in reflection mode at room temperature, using a Bruker D8 
Advance diffractometer provided with a Goebel Mirror and a PSD Vantec detector. A stepscanning mode was employed for the detector, with a $2 \theta$ step of $0.024^{\circ}$, at a rate of $0.5 \mathrm{~s}$ per step. $\mathrm{CuK}_{\alpha}$ (wavelength $\lambda=1.54 \AA$ ) radiation was used. Scanning Electron Microscopy (SEM) images were taken with a QUANTA 200 FEG ESEM on Au- metallized samples operating at an acceleration voltage of $1.5 \mathrm{kV}$ in high vacuum and using the detection of secondary electrons method.

$\mathrm{N}_{2}$ adsorption-desorption isotherms were measured at $-196{ }^{\circ} \mathrm{C}$ in a volumetric analyzer (3Flex, Micromeritics), in the relative pressure range $\left(\mathrm{P} / \mathrm{P}_{0}\right)$ from $10^{-5}$ to 1 bar. Previously, samples were degassed under vacuum at $250{ }^{\circ} \mathrm{C}$ for $10 \mathrm{~h}$ to remove humidity, adsorbed gases and solvent from the samples. The adsorption isotherms were used to determine the specific surface area $\left(\mathrm{S}_{\mathrm{BET}}\right)$ by applying the Brunauer-Emmet-Teller equation, the micropore volume $\left(\mathrm{V}_{\text {micro }}\right)$ using the DubininRadushkevich (DR) equation, and the total pore volume $\left(\mathrm{V}_{\text {total }}\right)$ from the amount adsorbed at 0.99 relative pressure. Pore size distributions (PSD) were evaluated using the 2D-NLDFT-HS model [ref]. Each isotherm was recorded in duplicate on fresh sample aliquots, to guarantee the reproducibility (error was below $5 \%$ ).

The palladium content in the porous polymer catalysts was determined using a radial simultaneous ICP-OES Varian 725-Es device.

\subsection{Synthesis of porous organic polymers}

The methodology of formation of POPs was based on a reaction described recently. ${ }^{30}$ Here, moreover, two reaction temperatures (room temperature and $60{ }^{\circ} \mathrm{C}$ ) and the use or not of chloroform, as a co-solvent, were tested. The 135TPB was combined with DAFO, isatin or a mixture of these monomers in molar DAFO/isatin ratios of $1 / 1$ and $1 / 3$. 
As an example, the synthesis of $135 \mathrm{TPB}-\mathrm{DAFO}-$ Isatin $(4: 3: 3)$ polymer network at $60{ }^{\circ} \mathrm{C}$ and using chloroform as co-solvent is described as follows:

An oven-dried three-necked Schlenk flask, $500 \mathrm{~mL}$, equipped with a mechanical stirred and nitrogen inlet and outlet was charged with 1,3,5-triphenylbenzene, 135TPB, (2.24 g, $7.32 \mathrm{mmol})$, isatin $(0.81 \mathrm{~g}, 5.49 \mathrm{mmol})$ and DAFO (1.00 g, $5.49 \mathrm{mmol})$. Anhydrous chloroform (15 mL) was added and monomers mixture was stirred at room temperature under a nitrogen blanket. The mixture was stirred and cooled at $0{ }^{\circ} \mathrm{C}$, and then chilled TFSA $(30 \mathrm{~mL})$ was added dropwise with an addition funnel for 30-60 min. After the TFSA addition, the mixture was left to warm up to room temperature and maintained with mechanical stirring for 24 hours. Subsequently, the mixture was warmed to $60{ }^{\circ} \mathrm{C}$ and maintained for $96 \mathrm{~h}$. Finally, the reaction mixture was poured onto cool distilled water, neutralized by adding a concentrated $\mathrm{NaHCO}_{3}$ solution, filtered and consecutively washed with warm distilled water, methanol, acetone and chloroform. After filtering, the powder was dried at $180{ }^{\circ} \mathrm{C}$ and 60 mbar during $24 \mathrm{~h}$. The material was obtained as a brown powder in quantitative yield (99\%).

\subsection{Synthesis of supported $\mathrm{Pd}(\mathrm{II})$ catalysts}

As an example, the synthesis of 135TPB-DAFO-isatin (4:3:3) coordinated with palladium(II) acetate is described below:

A $25 \mathrm{~mL}$ oven-dried Schlenk flask, with nitrogen inlet and outlet was charged with 135TPBDAFO-isatin (4:3:3) (0.75 g, $1.07 \mathrm{mmol}$ of DAFO groups) and $10 \mathrm{~mL}$ dichloromethane. The mixture was dispersed with an Ultra-turrax disperser at $6000 \mathrm{rpm}$, then palladium acetate $(0.24 \mathrm{~g}$, $1.07 \mathrm{mmol}$ ) was added and, finally, the mixture was stirred in the dark for $72 \mathrm{~h}$. The product was filtered and washed with dichloromethane and acetone. After drying it at $60{ }^{\circ} \mathrm{C}$ for $16 \mathrm{~h}$ under 60 mbar vacuum, the material was obtained as a brown powder in $99 \%$ yield. 


\subsection{General procedure for the Suzuki - Miyaura cross-coupling reaction}

Aryl halide $(0.50 \mathrm{mmol})$, arylboronic acid $(0.75-0.60 \mathrm{mmol})$, inorganic base $(1 \mathrm{mmol})$ and supported Pd (II) catalyst $(0.5-1 \% \mathrm{mmol} \mathrm{Pd})$ were added along with $5 \mathrm{~mL}$ of solvent $(\mathrm{EtOH} /$ water $(2: 3))$ in a $25 \mathrm{~mL}$ two-necked round bottom flask and heated at $80{ }^{\circ} \mathrm{C}$. The mixture was stirred by an ultrasonic probe under air. After the reaction was completed (between 0.5 and 2 $\mathrm{h}$ depending on the reactants), the mixture was extracted with dichloromethane, dried in a rotary evaporator and the conversion was evaluated by ${ }^{1} \mathrm{H}-\mathrm{RMN}$.

\subsection{Catalyst recycling of Suzuki-Miyaura cross-coupling reactions}

Recycling tests were made up as follows:

For the first cycle, aryl halide $(0.50 \mathrm{mmol})$, boronic acid $(0.60 \mathrm{mmol}), \mathrm{Na}_{2} \mathrm{CO}_{3}(1 \mathrm{mmol})$, POP-supported Pd(II) catalyst $(0.5 \% \mathrm{mmol})$ and $5 \mathrm{~mL}$ of solvent (EtOH/water $(2: 3))$ were added to a flask, and the mixture was reacting with ultrasonic, mechanical or magnetic stirring for $1 \mathrm{~h}$ at $80{ }^{\circ} \mathrm{C}$. Next, the mixture reaction along with $3 \mathrm{~mL}$ of EtOH was poured into a conical centrifuge tube and centrifuged at $4000 \mathrm{rpm}$ for $5 \mathrm{~min}$. The floating liquid was decanted and poured into a decantation funnel. The supported Pd(II) catalyst was centrifuged two more times with fresh EtOH and the floating liquid was also added to the decantation funnel. Then, the cross-coupling product was extracted in dichloromethane, the solvent was removed by rotatory evaporation and the final solid was characterized by ${ }^{1} \mathrm{H}-\mathrm{NMR}$ to determine the conversion of the reaction.

For the following cycles, the same quantity of reactants with the recovered catalyst, which was taken from the centrifuge tube with the solvent, were added to the flask. The same procedure followed in the first cycle was consecutively carried out a certain number of times. 


\section{RESULTS AND DISCUSSION}

\subsection{Optimization of reaction conditions}

The synthesis of POPs was achieved by reacting of a rigid trifunctional aromatic nucleophilic monomer having a $\mathrm{D}_{3 \mathrm{~h}}$ symmetry $(135 \mathrm{TPB})$ with ketones having electron-withdrawing groups (DAFO, isatin or a mixture of these monomers in specific molar ratios) under superacid conditions employing TFSA as the acid promoter. The polymerization reaction occurs when the strong acid protonates the electron deficient ketone, and reacts with an aromatic nucleophile. In order to form a highly crosslinked network, a stoichiometric ratio of trifunctional monomer to bifunctional monomer (or mixed of bifunctional monomers in different molar ratios) was employed. With the target of controlling the amount of metallic catalyst in the POPs, a set of copolymers were attained by combining DAFO with isatin in molar DAFO/isatin ratios of 1/1 and $1 / 3$. The structure of the materials and the acronyms used to refer to them are shown in Scheme 1. For comparative purposes, the homopolymer from $135 \mathrm{TBP}$ and isatin was also obtained using the reaction conditions previously reported. ${ }^{30}$

The synthesis of these POPs was optimized on varying reactions conditions, such as reaction temperature (room temperature, RT, or $60^{\circ} \mathrm{C}$ ) and use or not of a co-solvent (chloroform). Table S1 summarize the reaction conditions tested in the synthesis of POPs along with the reaction yields. According to the findings, the reaction yield of all the POPs were high $(>90 \%)$, except for that of POP3 prepared at $60{ }^{\circ} \mathrm{C}$ in TFSA. Particularly, the POPs were obtained in almost quantitative yields $(99 \%)$ when a TFSA/ $\mathrm{CHCl}_{3}$ mixture was employed. However, in those with a higher content of DAFO, POP1 and POP2, it was necessary to hold the reaction temperature at $60{ }^{\circ} \mathrm{C}$ for $96 \mathrm{~h}$. All the POPs prepared were characterized by FTIR-ATR and CP/MAS ${ }^{13} \mathrm{C}-\mathrm{NMR}$ (Figures S3-S10). Comparing the spectra, it was observed that the chemical structure of POP1 
and POP2, having higher percentage of DAFO, were strongly depended on temperature and reaction medium.

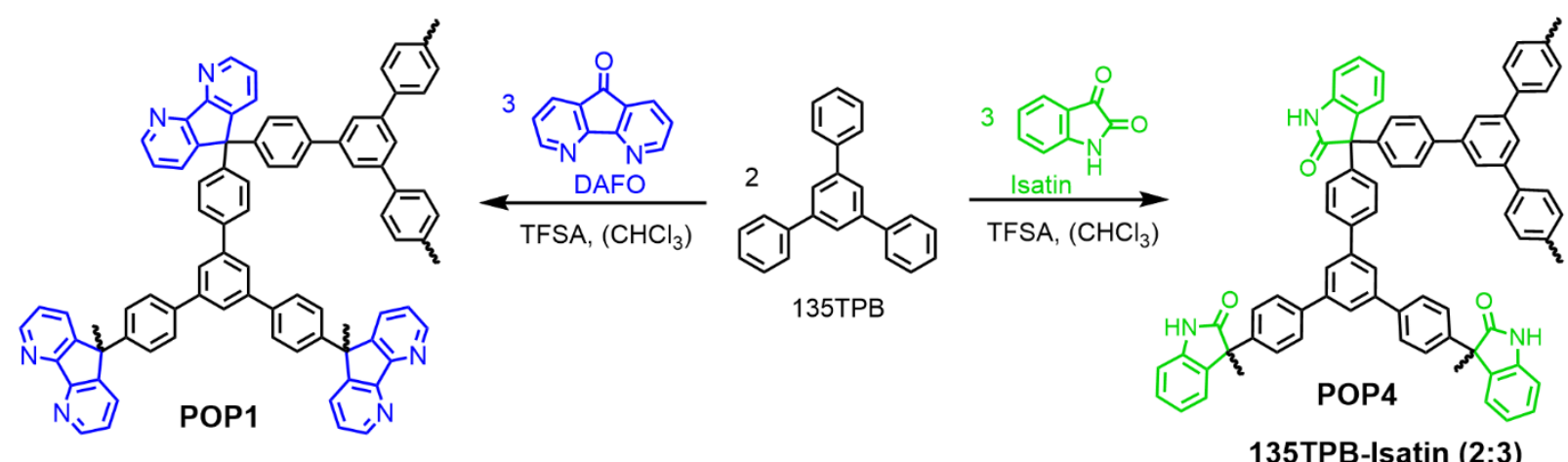

135TPB-DAFO (2:3)
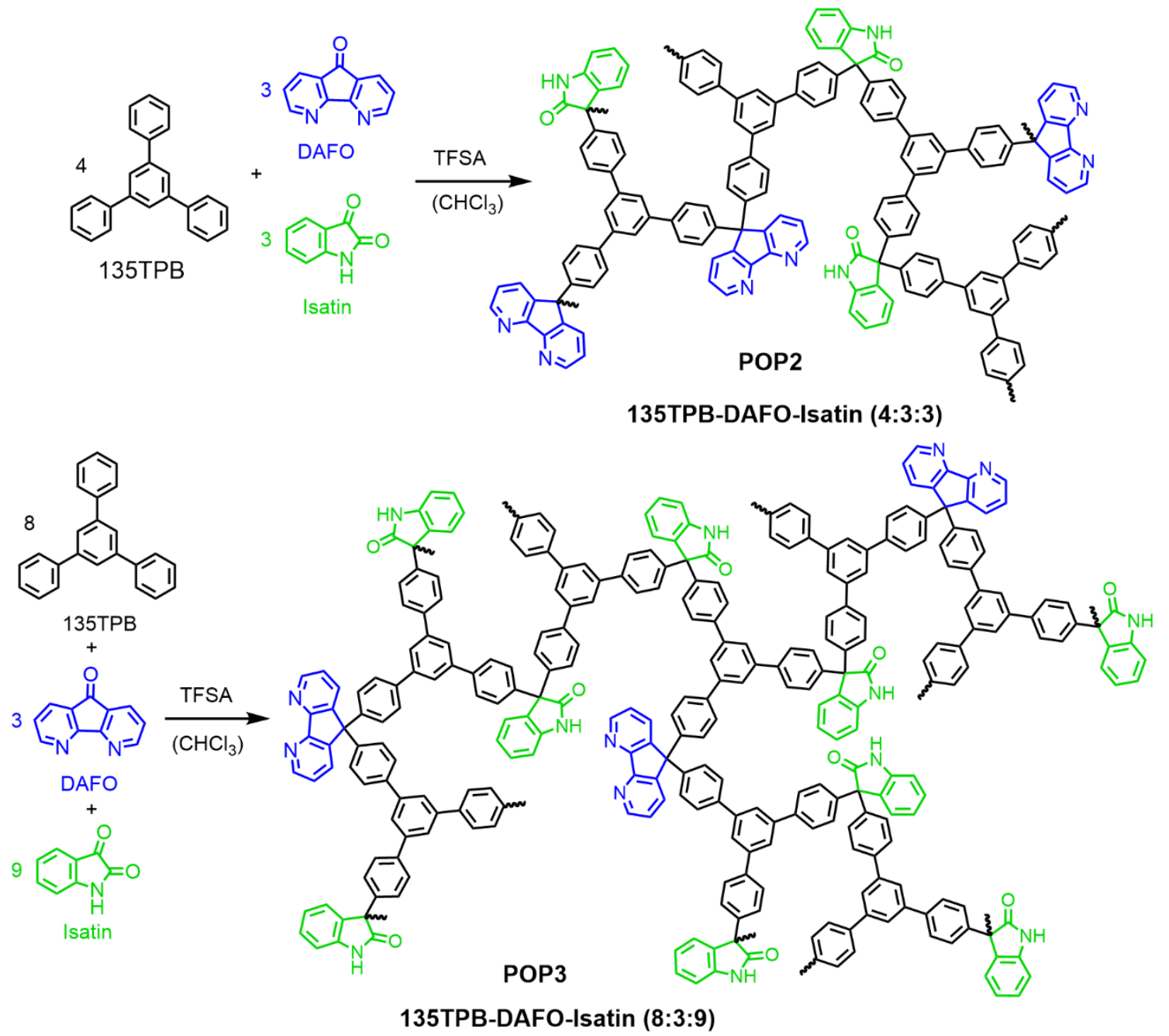

Scheme 1. Chemical structures of POPs. The numbers next to the monomers indicate the moles employed in the reaction. 
The thermal stability and surface area of these POPs were measured in order to pick out which of them would be employed as catalyst supports. The results of all the POPs obtained with high reaction yields are listed in Table 1. Moreover, the TGA thermograms of POPs, which were dried at $180^{\circ} \mathrm{C}$ for $24 \mathrm{~h}$, are shown in Figures S11-S14. Two losses were observed: a first one associated to the adsorbed water below $200{ }^{\circ} \mathrm{C}$ and a second one related to generalized degradation of material above $400{ }^{\circ} \mathrm{C}$. The DAFO-containing POPs that were prepared using a TFSA/ $\mathrm{CHCl}_{3}$ mixture showed an additional weight loss around $300{ }^{\circ} \mathrm{C}$, which could be presumably due to occluded solvent within the pores during the reaction.

According to the values summarized in Table 1 , the copolymers prepared at $60{ }^{\circ} \mathrm{C}$ and employing $\mathrm{CHCl}_{3}$ as co-solvent presented excellent thermal stabilities, above $500{ }^{\circ} \mathrm{C}$, and the highest $\mathrm{S}_{\mathrm{BET}}$, superior to $900 \mathrm{~m}^{2} / \mathrm{g}$. Thus, these copolymers were chosen for making the supported Pd(II) catalysts. Hereafter, they will be referred to as SP-POP1, SP-POP2 and SPPOP3. 
Table 1. Reaction yield, thermal properties and surface area $\left(\mathrm{S}_{\mathrm{BET}}\right)$ of POPs according to their reaction conditions.

\begin{tabular}{|c|c|c|c|c|c|}
\hline POP & Reaction conditions & $\begin{array}{l}\text { Reaction } \\
\text { yield } \\
(\%)\end{array}$ & $\begin{array}{l}\mathrm{Td} \\
\left({ }^{\circ} \mathrm{C}\right)\end{array}$ & $\begin{array}{l}\text { Char yield } \\
\text { at } 800{ }^{\circ} \mathrm{C} \\
(\%)\end{array}$ & $\begin{array}{l}\mathrm{S}_{\mathrm{BET}} \\
\left(\mathrm{m}^{2} \mathrm{~g}^{-1}\right)\end{array}$ \\
\hline POP1-RT & $\begin{array}{l}120 \mathrm{~h} / \mathrm{RT} \\
\mathrm{TFSA}\end{array}$ & 92 & 595 & 79 & 805 \\
\hline POP1-60 & $\begin{array}{l}24 \mathrm{~h} / \mathrm{RT}, 96 \mathrm{~h} / 60^{\circ} \mathrm{C} \\
\text { TFSA }\end{array}$ & 93 & 605 & 79 & 785 \\
\hline $\begin{array}{l}\mathrm{POP} 1-60 / \mathrm{CHCl}_{3} \\
\text { SP-POP1 }\end{array}$ & $\begin{array}{l}24 \mathrm{~h} / \mathrm{RT}, 96 \mathrm{~h} / 60^{\circ} \mathrm{C} \\
\mathrm{TFSA} / \mathrm{CHCl}_{3}\end{array}$ & 99 & 545 & 76 & 920 \\
\hline POP2-60 & $\begin{array}{l}24 \mathrm{~h} / \mathrm{RT}, 96 \mathrm{~h} / 60^{\circ} \mathrm{C} \\
\text { TFSA }\end{array}$ & 93 & 545 & 79 & 550 \\
\hline $\begin{array}{l}\mathrm{POP} 2-60 / \mathrm{CHCl}_{3} \\
\text { SP-POP2 }\end{array}$ & $\begin{array}{l}24 \mathrm{~h} / \mathrm{RT}, 96 \mathrm{~h} / 60^{\circ} \mathrm{C} \\
\mathrm{TFSA} / \mathrm{CHCl}_{3}\end{array}$ & 99 & 525 & 75 & 930 \\
\hline $\mathrm{POP} 3-\mathrm{RT} / \mathrm{CHCl}_{3}$ & $\begin{array}{l}120 \mathrm{~h} / \mathrm{RT} \\
\mathrm{TFSA} \mathrm{CHCl}_{3}\end{array}$ & 99 & 570 & 75 & 820 \\
\hline $\begin{array}{l}\mathrm{POP} 3-60 / \mathrm{CHCl}_{3} \\
\text { SP-POP3 }\end{array}$ & $\begin{array}{l}24 \mathrm{~h} / \mathrm{RT}, 96 \mathrm{~h} / 60^{\circ} \mathrm{C} \\
\mathrm{TFSA} / \mathrm{CHCl}_{3}\end{array}$ & 99 & 565 & 77 & 935 \\
\hline $\mathrm{POP} 4-\mathrm{RT} / \mathrm{CHCl}_{3}$ & $\begin{array}{l}120 \mathrm{~h} / \mathrm{RT} \\
\mathrm{TFSA} \mathrm{CHCl}_{3}{ }^{\mathrm{a}}\end{array}$ & 99 & 565 & 70 & 760 \\
\hline
\end{tabular}

\subsection{Characterization of catalyst supports}

As highly crosslinked materials, all POPs were insoluble in organic solvent, in very low $\mathrm{pK}_{\mathrm{a}}$ acids and in high $\mathrm{pK}_{\mathrm{a}}$ bases, showing excellent chemical stability. ATR-FTIR and CP/MAS ${ }^{13} \mathrm{C}$ NMR spectra of the SP-POPs selected as catalyst supports were compared with the 
corresponding POP4 (135TPB-isatin) in Figures 1 and 2, respectively. The absorption bands at 1712,1467 and $1320 \mathrm{~cm}^{-1}$ were assigned to the 5-membered lactam rings coming from isatin. The weak $\mathrm{C}=\mathrm{O}$ stretching band around $1710 \mathrm{~cm}^{-1}$ in the spectra of SP-POP1 confirmed the reaction of DAFO. In the case of the copolymers, the band at $1570 \mathrm{~cm}^{-1}$, which was attributed to the $\mathrm{C}=\mathrm{N}$ stretching from $\mathrm{DAFO}$, was not clearly visible. The $\mathrm{CP} / \mathrm{MAS}{ }^{13} \mathrm{C} \mathrm{NMR}$ spectra confirmed the reaction of the ketones with the aromatic rings; all of them showed a signal at 60 ppm corresponding to the quaternary sp3 carbons. The more characteristic peaks derived from DAFO and isatin moieties are indicated in the spectra. The other signals, between 135-115 ppm, were assigned to aromatic carbons.

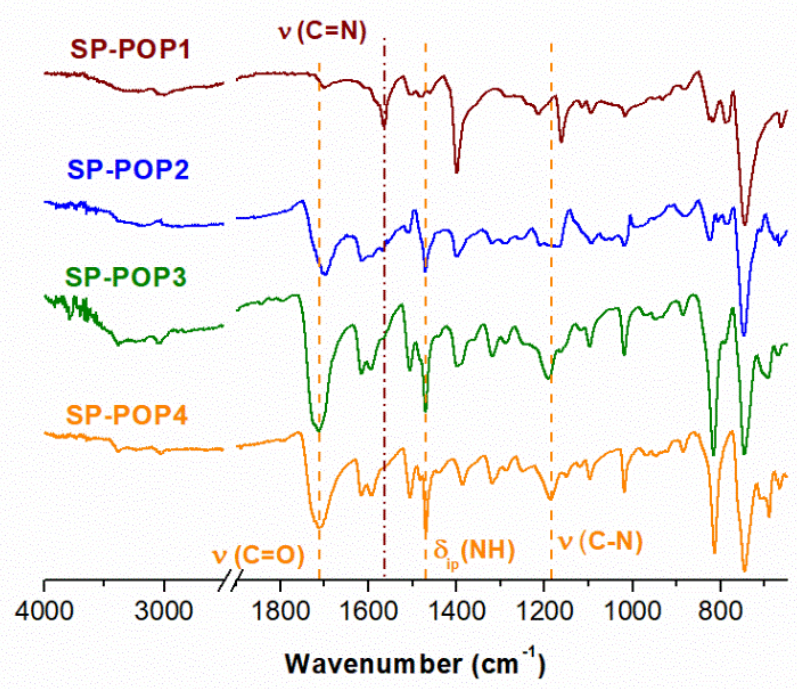

Figure 1. ATR-FTIR spectra of POP-based supports. The POP4 spectrum has been included for comparison. The dashed lines indicate the position of the characteristic bands of POPs. 


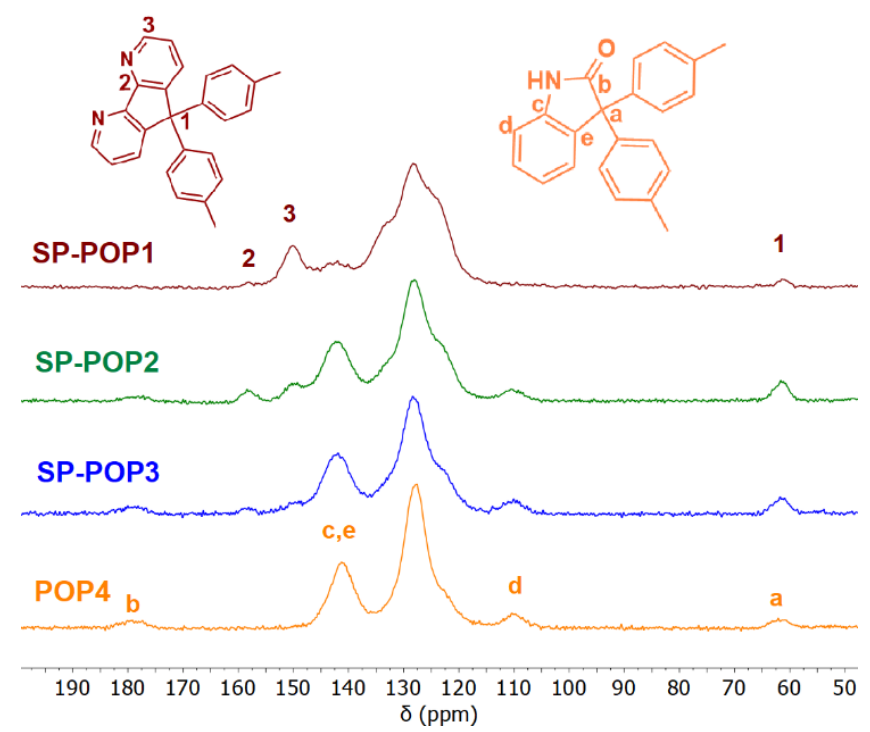

Figure 2. CP/MAS 13C NMR spectra of POP-based supports. The POP4 spectrum has been included for comparison.

The amorphous nature of these materials was confirmed by WAXS. The patterns of SP-POPs are compared to that of POP4 in Figure 3. All of them showed similar amorphous halos with three maxima around $14^{\circ}, 20^{\circ}$ and $42^{\circ}$, indicating some regularity in the chains' packing presumably due to the flat and symmetrical triangular shape of the 135TPB. According to according to Bragg's law ( $\lambda=2 \mathrm{~d} \operatorname{sen} \theta$, being $\theta$ the scattering angle), these maxima corresponded to $0.64,0.44$ and $0.21 \mathrm{~nm}$. 


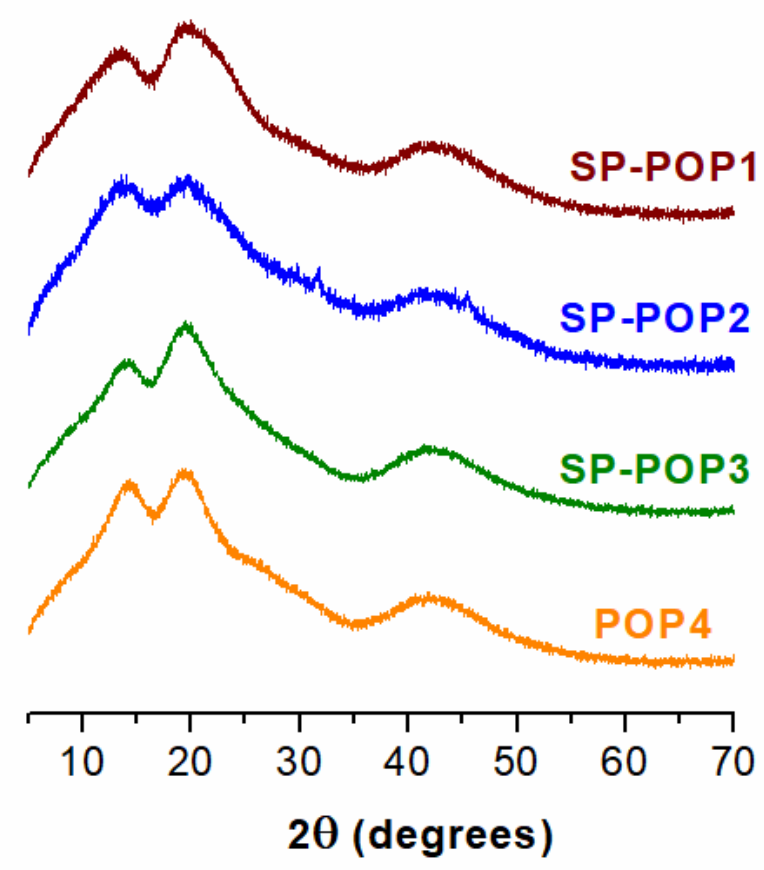

Figure 3. WAXS patterns of POP-based supports. The POP4 pattern has been included for comparison.

The surface morphology of the three SP-POPs was explored by FE-SEM. Figure 4 compares the images of these catalyst supports with that of POP4 (135TPB-Isatin). The images of SPPOP1 and SP-POP2, having a higher content of DAFO, revealed very small size particles that form a homogeneous rough surface in which small agglomerates were visible. When the content of isatin was higher, such as in SP-POP3, the surface was rougher due to presence of a higher amount of agglomerates with irregular shapes. 

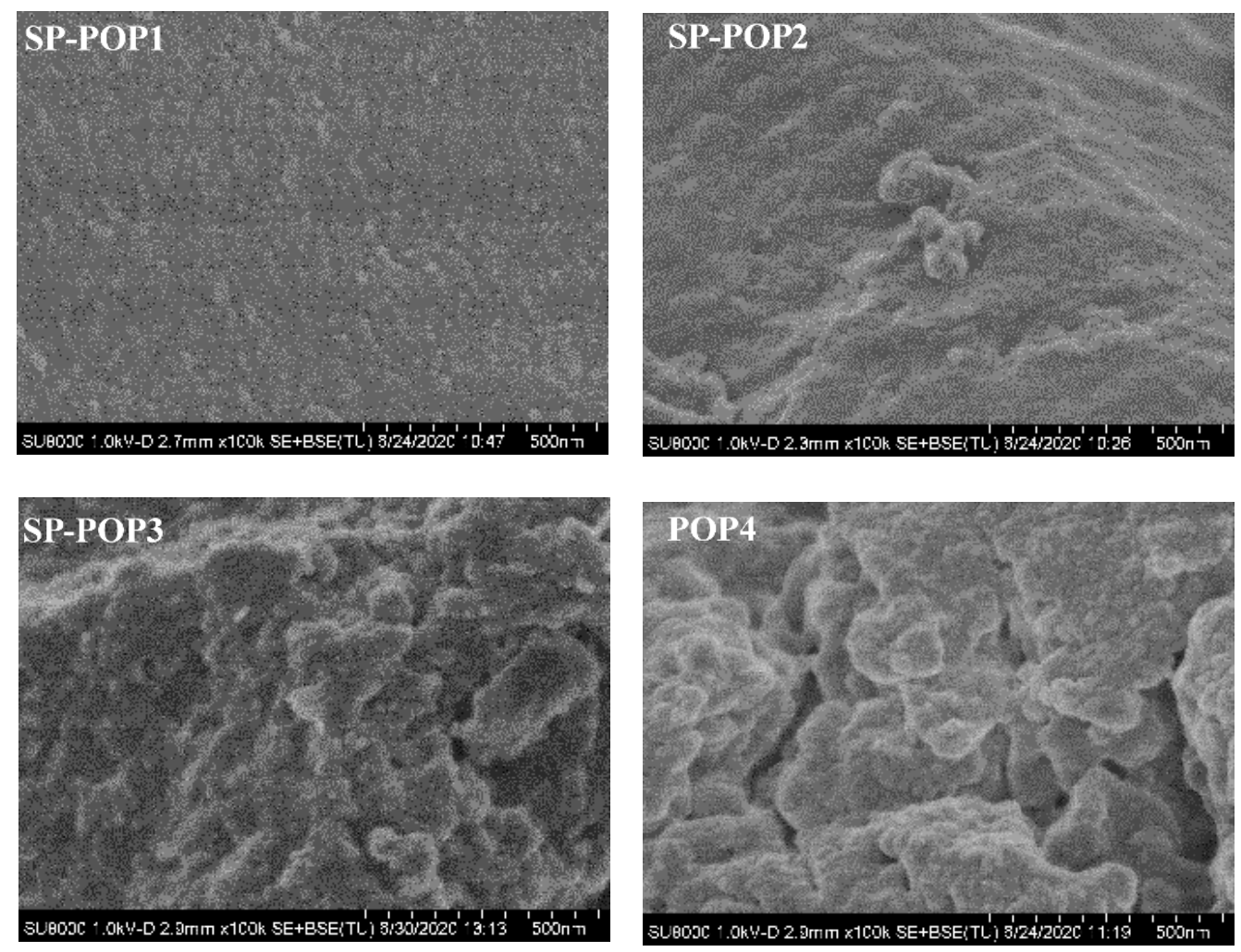

Figure 4. FE-SEM images of SP-POPs. The POP4 image is included for comparison.

The porosity of SP-POPs was studied from the $\mathrm{N}_{2}$ adsorption/desorption isotherms at $-196{ }^{\circ} \mathrm{C}$, depicted in Figure 5. As indicated above, prior to measurements, the samples were dried at $250{ }^{\circ} \mathrm{C}$ under vacuum for $10 \mathrm{~h}$. The SP-POPs showed a high uptake at low relative pressures $\left(\mathrm{P} / \mathrm{P}_{0}<0.01\right)$, which indicated the presence of micropores. ${ }^{33}$ Furthermore, a significant hysteresis was observed in the desorption branch in the whole range of relative pressures. This behavior, indicative of the presence of constricted porosity, was more pronounced in sample SP-POP3, and it has already been reported in analogous materials derived from aromatic trifunctional monomers, such as triptycene and 135TPB, and ketones, such as isatin and 2,2,2trifluoroacetophenone. ${ }^{30}$ The volume difference between the adsorption and desorption branches was higher in the case of SP-POP3, with an additional $\mathrm{N}_{2}$ uptake at relative pressure $\mathrm{P} / \mathrm{P}_{0}=0.22$ of $24 \%$. The SP-POP1 and SP-POP2, having the higher percentage of DAFO, showed a similar 
behaviour. The step increase in the amount of gas adsorbed at relative pressures above 0.98 is attributed to nitrogen condensation in the interstitial voids of the polymer particles.

Figure 5 ( $b$ and $c$ ) show the pore size distributions of the samples; as seen, all three SP-POPs exhibited a marked contribution of micropores, with a peak centred at $0.50 \mathrm{~nm}$ for SP-POP1 and SP-POP2 and at 0.61 for SP-POP3 and a tail of lower intensity spanning in the range 1-10 nm.

The main textural parameters and the skeletal density of SP-POPs are summarized in Table 2. The porosity of all three SP-POPs was estimated to be close to $35 \%$; the contribution of the microporosity to the total porosity was around $75 \%$ for samples SP-POP1 and SP-POP2, whereas it accounted for ca. $65 \%$ for sample SP-POP3. This corroborated the microporous character of these catalytic supports.
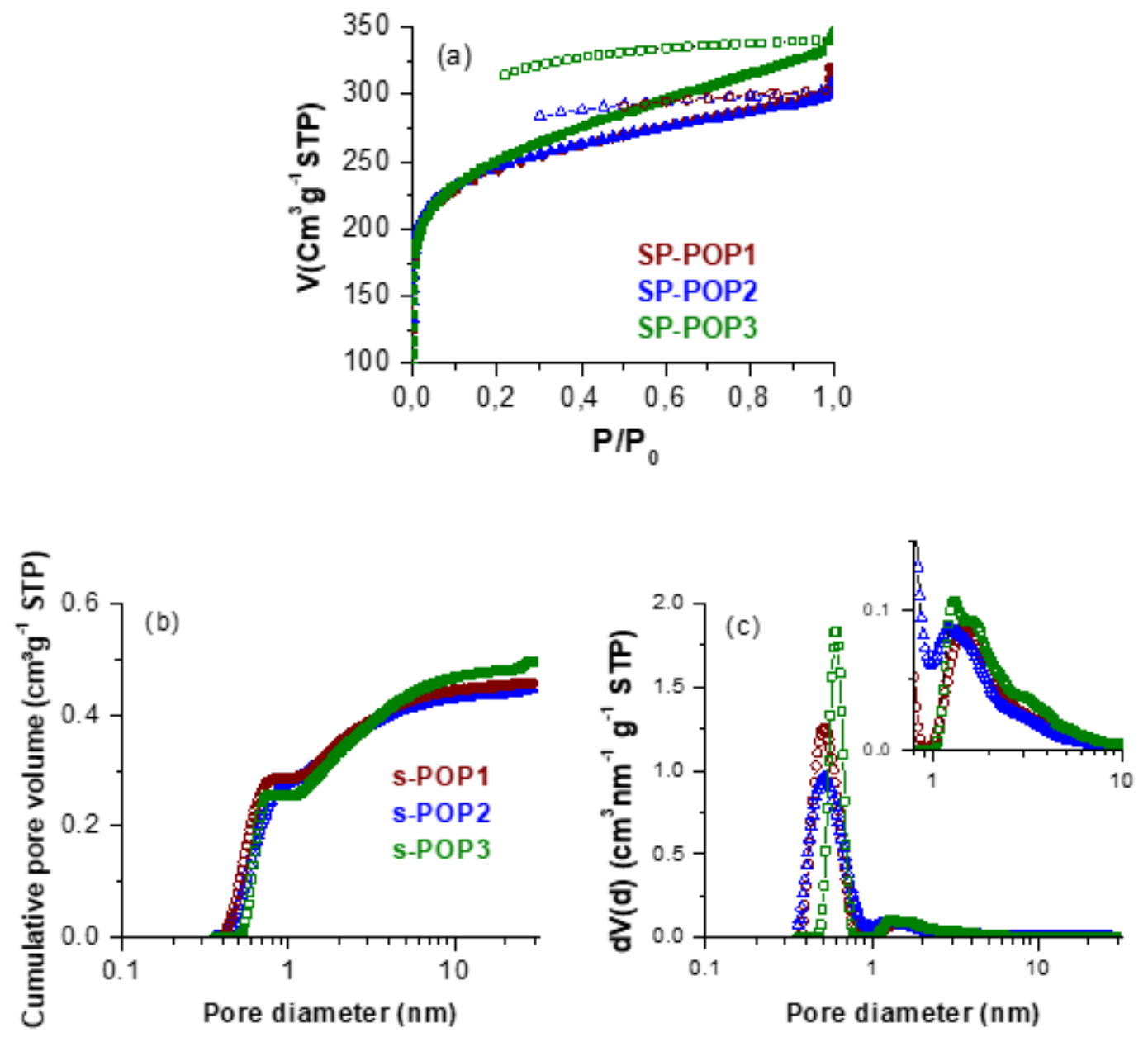
Figure 5. (a) $\mathrm{N}_{2}$ adsorption (full symbols)/desorption (empty symbols) isotherms measured at $-196{ }^{\circ} \mathrm{C}$; (b) cumulative pore volume and (c) pore size distribution of the POP-based catalyst supports.

Table 2. Density and porosity parameters from $\mathrm{N}_{2}$ adsorption isotherms.

\begin{tabular}{lllllll}
\hline SP-POP & density $^{a}$ & $\mathrm{~S}_{\mathrm{BET}}{ }^{b}$ & $\mathrm{~V}_{\text {total }}{ }^{c}$ & $\mathrm{~V}_{\text {micro }}{ }^{d}$ & $\begin{array}{l}\text { Porosity }^{e} \\
(\%)\end{array}$ & Microporosity $^{\mathrm{r}}$ \\
\hline SP-POP1 & 1.044 & 920 & 0.47 & 0.36 & 33 & 77 \\
SP-POP2 & 1.125 & 930 & 0.46 & 0.35 & 34 & 76 \\
SP-POP3 & 0.996 & 935 & 0.53 & 0.34 & 34 & 64 \\
\hline
\end{tabular}

${ }^{a}$ skeletal density $\left(\mathrm{g} \mathrm{cm}^{-3}\right)$ measurement by Helium picnometry; ${ }^{b}$ Specific surface area $\left(\mathrm{m}^{2} \mathrm{~g}^{-1}\right)$ calculate by BET equation; ${ }^{c}$ Total pore volume $\left(\mathrm{cm}^{3} \mathrm{~g}^{-1}\right)$ calculated at $\mathrm{P} / \mathrm{P}_{0}=0.99 ;{ }^{d}$ Micropore volume $\left(\mathrm{cm}^{3} \mathrm{~g}^{-1}\right)$, calculated from DR equation; ${ }^{e}$ Porosity $(\%)$ defined as ratio from $\mathrm{V}_{\text {total }}$ to $\left(\mathrm{V}_{\text {total }}+(1 /\right.$ density $\left.)\right) ;{ }^{\mathrm{f}}$ microporosity fraction, defined as the ratio $\mathrm{V}_{\text {micro }} / \mathrm{V}_{\text {total }}(\%)$.

\subsection{Characterization of Pd-supported catalysts}

Palladium(II) coordination reaction of catalyst support was carried out by direct mixing the SP-POP with $\mathrm{Pd}(\mathrm{OAc})_{2}$, as already described in the Experimental section. Hereafter, these materials will be referred to as Pd@SP-POPx, where $\mathrm{x}$ is 1,2 or 3 according to the catalyst support. The ATR-FTIR spectra (Figure 6) showed two peaks at 1700 and $1359 \mathrm{~cm}^{-1}$ that were assigned to the acetate groups of the $\mathrm{Pd}(\mathrm{OAc})_{2}$ bipyridine complexes. ${ }^{34}$ The asymmetric $\mathrm{COO}^{-}$ stretching band at $1700 \mathrm{~cm}^{-1}$ was clearly visible in Pd@SP-POP1 because the catalyst support does not have carbonyl groups in its structure (cf. Figure 1). In the two other supported Pd(II) catalysts, this band overlapped with the $\mathrm{C}=\mathrm{O}$ band derived from carbonyl group of lactam rings. 


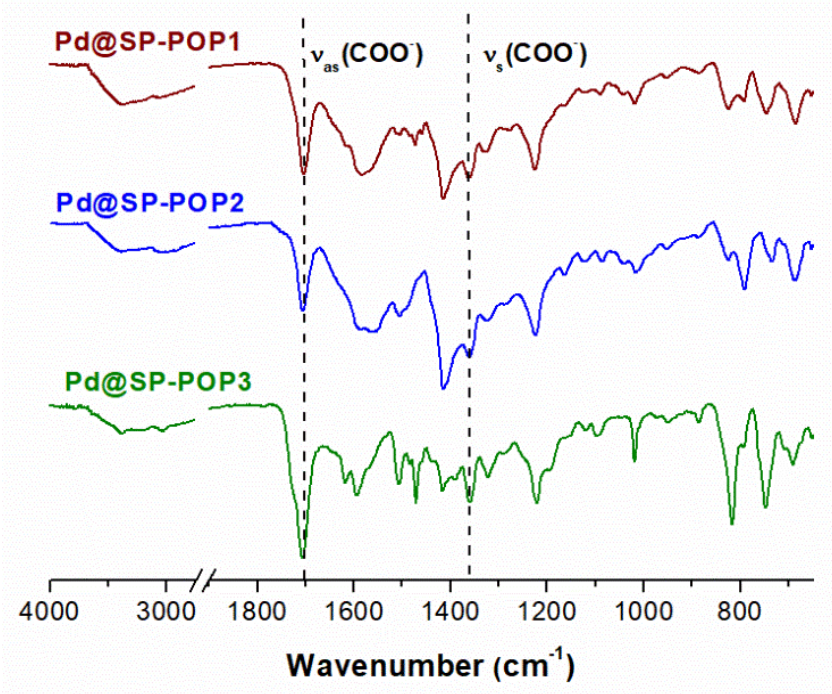

Figure 6. ATR-FTIR spectra of Pd-supported catalysts. The dashed lines indicate the position of the characteristic bands of briding $\mathrm{COO}^{-}$groups coming from $\mathrm{Pd}(\mathrm{OAc})_{2}$.

The WAXS patterns of Pd-supported catalysts, depicted in Figure 7, showed very weak reflections around $12^{\circ}$ and $33^{\circ}$, which could come from $\mathrm{Pd}(\mathrm{OAc})_{2}{ }^{35}$ Comparing the amorphous halos of Pd@SP-POPxs with those corresponding to the precursor porous polymers, significant changes in the patterns were observed, especially in the Pd@SP-POP1 and Pd@SP-POP2. In these cases, the patterns of supported Pd(II) catalysts showed broader maxima and a lower intensity ratio between them, as compared to those of precursor porous polymers. This finding seems to indicate that the formation of $\mathrm{Pd}(\mathrm{II})$ bipyridine complexes mainly led to a higher contribution of small intersegmental distances (high scattering angle side) to the global scattering and, then, a change in the packing of catalyst support could be possible. 


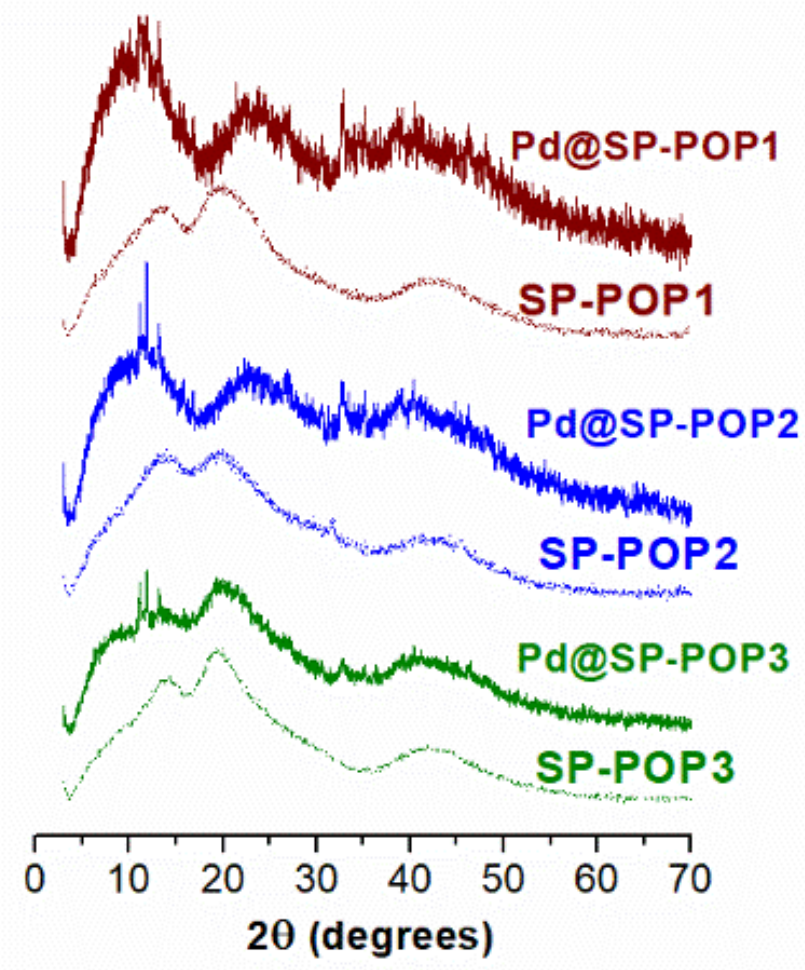

Figure 7. WAXS patterns of Pd-supported catalysts. WAXS patterns of precursor porous polymers (dashed lines) have been included for comparison.

The concentration of $\mathrm{Pd}$ in the catalyst supports was determined by ICP-OES and the values are listed in Table 3. The load amount of Pd embedded in all the SP-POPs was around 95\%, related to the theoretical value calculated from their bipyridine content.

Table 3. Pd content of POP supported Pd(II) catalysts

\begin{tabular}{lll}
\hline catalyst & \multicolumn{2}{l}{ Pd content $\left(\mathrm{mg} \mathrm{g}^{-1}\right)$} \\
\cline { 2 - 3 } & Experimental $^{a}$ & Theoretical $^{b}$ \\
\hline Pd@SP-POP1 & 172 & 180 \\
Pd@SP-POP2 & 111 & 115
\end{tabular}


${ }^{a}$ Determined by ICP-OES. ${ }^{b}$ Calculated from its bipyridine content.

\subsection{Catalytic activity}

The cross-coupling reaction of 4-bromoanisol with phenylboronic acid was tested for all the Pd@SP-POP catalysts, employing classical Suzuki-Miyaura conditions. Yields were very high (quantitative), as seen in Table S2.

The Pd@SP-POP2 was picked out to evaluate its catalytic activity for Suzuki-Miyaura crosscoupling reaction of aryl halides with phenylboronic acid. This choice was made attending to its Pd load (around 10\%), to the value of $\mathrm{S}_{\mathrm{BET}}$ and microporosity percentage of the precursor porous polymer relative to the two other supports studied (cf. Table 2). In addition, the cost of the material, the DAFO monomer is much more expensive than isatin, and SP-POP2 is economically more competitive than SP-POP1. SP-POP3 was not considered due to the relatively low value of Pd load.

In a first stage, the Suzuki-Miyaura coupling reaction of 4-bromotoluene with phenylboronic acid at $80{ }^{\circ} \mathrm{C}$, using aerobic conditions, was chosen as a model for optimizing reaction parameters such as the employed solvent and base. Different solvents and bases were tested, as seen in Table 4. Excellent yields of the cross-coupling product were obtained using $\mathrm{DMF} / \mathrm{H}_{2} \mathrm{O}$ $(2 / 3)$ and $\mathrm{EtOH} / \mathrm{H}_{2} \mathrm{O}(2 / 3)$ mixtures as solvent in presence of bases such as $\mathrm{Cs}_{2} \mathrm{CO}_{3}$ and $\mathrm{Na}_{2} \mathrm{CO}_{3}$. According to these findings and the essential goal of employing green reagents, the EtOH/ $\mathrm{H}_{2} \mathrm{O}$ $(2 / 3)$ mixture and the $\mathrm{Na}_{2} \mathrm{CO}_{3}$ were selected for this study.

Table 4- The optimization of reaction parameters for the Suzuki-Miyaura reaction of 4bromotoluene with phenylboronic acid ${ }^{\mathrm{a}}$ 


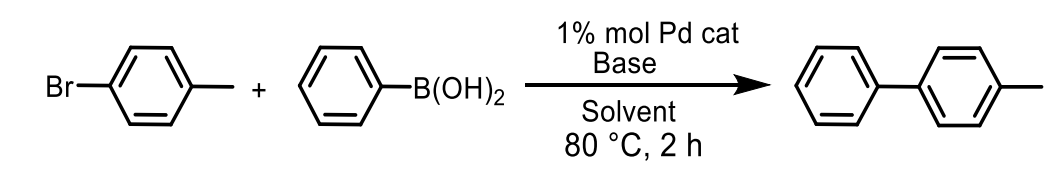

\begin{tabular}{llll}
\hline Entry & Base & Solvent & \% Conversion \\
\hline 1 & $\mathrm{Cs}_{2} \mathrm{CO}_{3}$ & EtOH/ $\mathrm{H}_{2} \mathrm{O} \mathrm{(2:3)}$ & 94 \\
2 & $\mathrm{Na}_{2} \mathrm{CO}_{3}$ & EtOH/ $\mathrm{H}_{2} \mathrm{O}(2: 3)$ & 99 \\
3 & $\mathrm{Cs}_{2} \mathrm{CO}_{3}$ & $\mathrm{DMF} / \mathrm{H}_{2} \mathrm{O}(2: 3)$ & 99 \\
4 & $\mathrm{Na}_{2} \mathrm{CO}_{3}$ & $\mathrm{DMF} / \mathrm{H}_{2} \mathrm{O}(2: 3)$ & 99 \\
5 & $\mathrm{Cs}_{2} \mathrm{CO}_{3}$ & $\mathrm{CH}_{3} \mathrm{CN} / \mathrm{H}_{2} \mathrm{O}(3: 1)$ & 61 \\
6 & $\mathrm{Na}_{2} \mathrm{CO}_{3}$ & $\mathrm{CH}_{3} \mathrm{CN} / \mathrm{H}_{2} \mathrm{O}(3: 1)$ & 53 \\
\hline
\end{tabular}

${ }^{a}$ Reaction conditions: 4-bromotoluene $(1 \mathrm{mmol})$, phenylboronic acid $(1.5 \mathrm{mmol})$, base (2 mmol), Pd@SP-POP2 (1\% aryl derivative/catalyst) and solvent $(10 \mathrm{~mL}) .{ }^{\mathrm{b}}$ Conversion values were obtained by ${ }^{1} \mathrm{H}-\mathrm{RMN}$.

In a second stage, a set of coupling reactions were made, reducing the reaction time and the amount of Pd@SP-POP2, employing other aryl bromides and chlorides with electron-donating groups (tert-butyl and $\mathrm{OCH}_{3}$ groups), as shown in Table 5. In the case of the reaction of 4bromotoluene in $\mathrm{EtOH} / \mathrm{H}_{2} \mathrm{O}(2 / 3)$, the reduction of reaction time to 1 hour (Entry 7) or lessening the amount of Pd-supported catalyst in half (Entry 8) led to lower conversions of reaction than that obtained previously (Entry 6). The reaction of 1-bromo-4-tert-butylbenzene with phenylboronic acid for $1 \mathrm{~h}$ resulted in $45 \%$ conversion (Entry 9), which was much lower than the conversions obtained for 1-bromotoluene (Entry 7) and 4-bromoanisol (Entry 11) under the same reaction conditions. This finding could be explained under the assumption of a lower diffusion transport of 1-bromo-4-tert-butylbenzene through the pores due to the low solubility of the aryl derivative in the solvent mixture. In order to solve this problem, the use of a solvent mixture able to dissolve more efficiently the reagents was considered. Thus, when an $\mathrm{EtOH} / \mathrm{H}_{2} \mathrm{O}$ volume ratio of 3/2 was used, the conversion of coupling reaction was much higher (97\%) (Entry 10). As to 
the 4-bromoanisol, the complete conversion achieved led us to attempt to change some other reaction parameter from Entry $11: 1)$ reducing the reaction time to $0.5 \mathrm{~h}$ (Entry 12$)$ and 2$)$ and lowering the amount of catalyst at $0.5 \%$ mol (Entry 13). None of these changes significantly decreased the reaction yields and the conversions remained higher than $87 \%$.

Aryl chloride derivative, 4-chorotoluene, was also tested to evaluate the differential catalytic activity of Pd@SP-POP2 in the Suzuki-Miyaura reaction between bromo and chloro substituents. The reaction conversion of 4-chlorotoluene (Entry 14) was moderated (around 70\%) as compared with its bromo analogue employing the same conditions (Entry 7). The use of a 3/2 EtOH/ $\mathrm{H}_{2} \mathrm{O}$ mixture (Entry 15 ) did not improve the cross-coupling reaction conversion. The products of reaction were determined by GC-MS analysis and the formation of 4,4'dimethybiphenyl (homocoupling compound formed from 4-chlorotoluene) was observed. This unexpected fact may be interesting to employ this type of catalysts in homocoupling reactions.

Table 5- Suzuki-Miyaura reactions of aryl bromides and chlorides with phenylboronic acid catalyzed by Pd@SP-POP2 catalyst

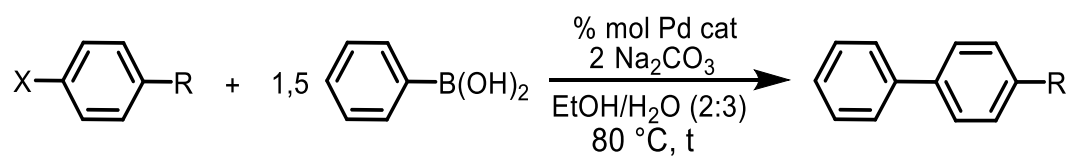




\begin{tabular}{llllll}
\hline Entry & $\mathrm{X}$ & $\mathrm{R}$ & $\begin{array}{l}\text { Pd cat. } \\
(\% \mathrm{~mol})\end{array}$ & $\begin{array}{l}\text { Time } \\
(\mathrm{h})\end{array}$ & $\begin{array}{l}\text { Conversion }^{a} \\
(\%)\end{array}$ \\
\hline 6 & $\mathrm{Br}$ & $\mathrm{CH}_{3}$ & 1 & 2 & 99 \\
7 & $\mathrm{Br}$ & $\mathrm{CH}_{3}$ & 1 & 1 & 90 \\
8 & $\mathrm{Br}$ & $\mathrm{CH}_{3}$ & 0.5 & 2 & 96 \\
9 & $\mathrm{Br}$ & ${ }^{\mathrm{t}} \mathrm{Bu}$ & 1 & 1 & 45 \\
$10^{\mathrm{b}}$ & $\mathrm{Br}$ & ${ }^{\mathrm{t}} \mathrm{Bu}$ & 1 & 1 & 97 \\
11 & $\mathrm{Br}$ & $\mathrm{OCH}_{3}$ & 1 & 1 & 100 \\
12 & $\mathrm{Br}$ & $\mathrm{OCH}_{3}$ & 1 & 0.5 & 95 \\
13 & $\mathrm{Br}$ & $\mathrm{OCH}_{3}$ & 0.5 & 1 & 87 \\
14 & $\mathrm{Cl}$ & $\mathrm{CH}_{3}$ & 1 & 1 & 68 \\
$15^{\mathrm{b}}$ & $\mathrm{Cl}$ & $\mathrm{CH}_{3}$ & 1 & 1 & 71 \\
\hline
\end{tabular}

${ }^{a}$ Conversion values obtained by ${ }^{1} \mathrm{H}-\mathrm{RMN} .{ }^{b}$ The EtOH$/ \mathrm{H}_{2} \mathrm{O}$ solvent ratio was $3: 2$.

In view of the excellent conversions obtained using an excess of $1.5 \mathrm{~mol}$ of phenylboronic acid per $1 \mathrm{~mol}$ of aryl halide, the ratio of boronic acid/aryl bromide was reduced to 1.2, resulting also in high reactions conversions, as seen in Table 6.

The number of catalytic conversions (TON) and the frequency of conversions (TOF) for the reaction of 4-bromoanisol and phenylboronic acid were determined for a conversion value of $8 \%$, using $0.023 \% \mathrm{~mol}$ of $\mathrm{Pd}$ and a reaction time of $15 \mathrm{~min}$. The obtained values were excellent with values of 1580 and $7900 \mathrm{~h}^{-1}$ for TON and TOF, respectively. ${ }^{36}$

Table 6- Suzuki-Miyaura reactions of aryl bromides with arylboronic acid, varying the ratio between the reagents, catalysed by Pd@SP-POP2 catalyst

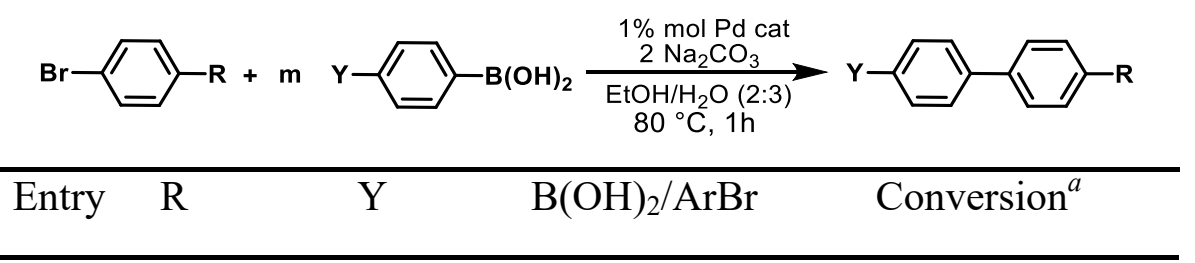




\begin{tabular}{lllll}
\hline & & & ratio & $(\%)$ \\
\hline 7 & $\mathrm{CH}_{3}$ & $\mathrm{H}$ & 1.5 & 90 \\
15 & $\mathrm{CH}_{3}$ & $\mathrm{H}$ & 1.2 & 79 \\
11 & $\mathrm{OCH}_{3}$ & $\mathrm{H}$ & 1.5 & $>99$ \\
16 & $\mathrm{OCH}_{3}$ & $\mathrm{H}$ & 1.2 & $>99$ \\
$10^{\mathrm{b}}$ & ${ }^{\mathrm{t}} \mathrm{Bu}$ & $\mathrm{H}$ & 1.5 & 97 \\
$17^{\mathrm{b}}$ & ${ }^{\mathrm{t}} \mathrm{Bu}$ & $\mathrm{H}$ & 1.2 & 97 \\
18 & $\mathrm{CH}_{3}$ & $\mathrm{OCH}_{3}$ & 1.2 & 99 \\
\hline
\end{tabular}

${ }^{a}$ Conversion values obtained by ${ }^{1} \mathrm{H}-\mathrm{RMN} .{ }^{b} \mathrm{EtOH} / \mathrm{H}_{2} \mathrm{O}$ solvent ratio was 3:2.

The effectiveness of the Pd-supported catalyst with bulky and difunctional aryl halides and phenylboronic acid and 4-methoxyphenylboronic acid was also tested. The reactions yielded excellent conversions, as seen in Table 7. In particular, Pd@SP-POP2 was able to produce a quantitative yield of the monomer 5'-butyl-m-terphenyl (Entry 20). The compound 4-4"dimetoxy-5'-t-butyl-m-terphenylene, which is precursor of 4-4"-dihydroxy-3,3"'-diamino-mterphenylene (Entry 22), which could be used as a monomer able to produce thermally rearranged materials,${ }^{37}$ was obtained with a yield of $81 \%$. A reaction made in our lab, using 4methoxyphenilboronic acid, 5-t-butyl-1,3-dibromobenzene and tetrakis(triphenylphosphine)palladium $(0)(4 \%)$, using a mixture of toluene/water at $100^{\circ} \mathrm{C}$, gave a yield around $75 \%$.

Table 7- Suzuki-Miyaura reactions of bulky reagents catalysed by Pd@SP-POP2

Entry Reaction

Conversion $^{a}$ 

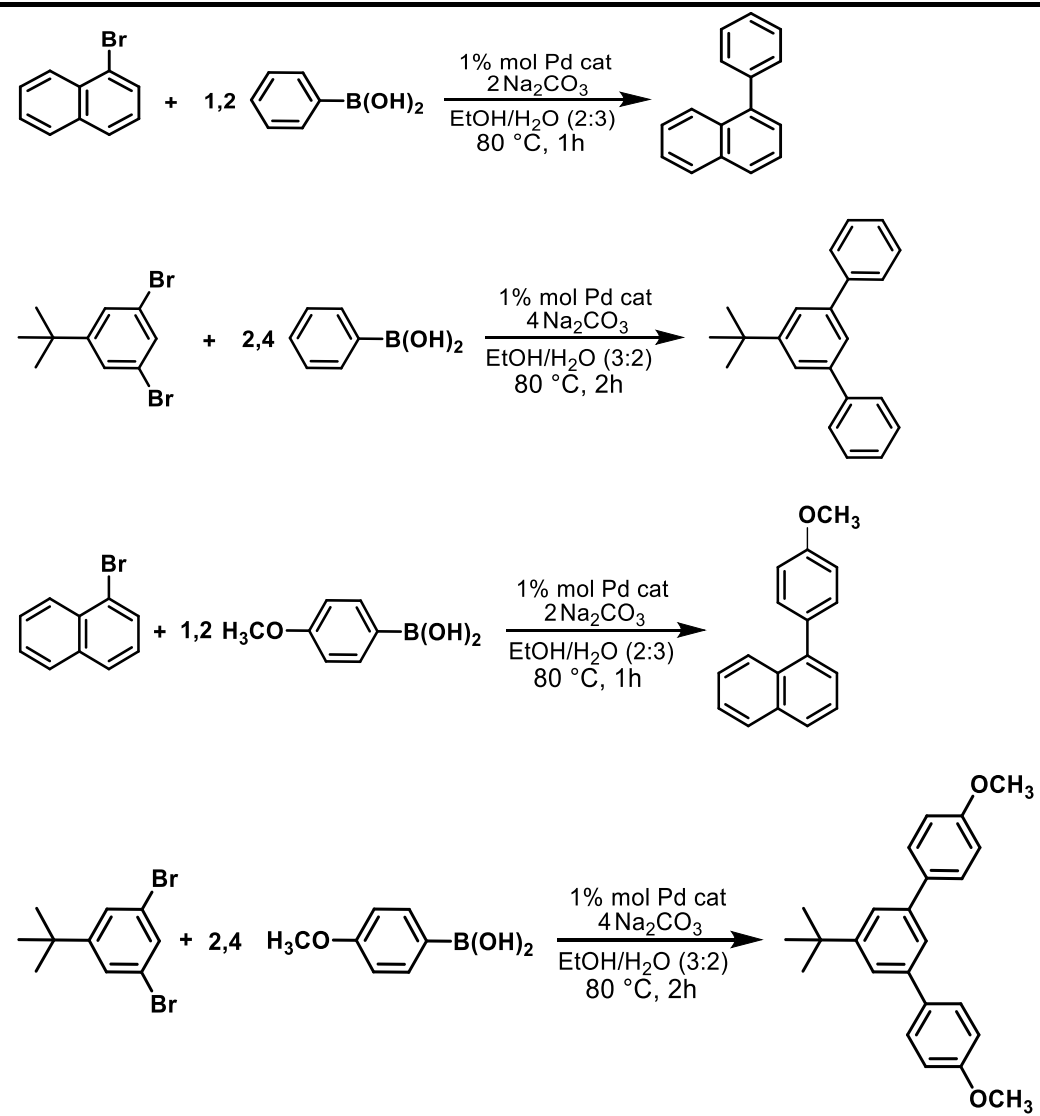

\section{${ }^{a}$ Conversion values obtained by ${ }^{1} \mathrm{H}-\mathrm{RMN}$.}

\subsection{Scale-up of Suzuki-Miyaura reactions}

After the optimization process, scale-up of two of Suzuki-Miyaura reactions tested were carried out by reacting 20-fold the quantity of reagents employed during the catalysis study.

The first scale-up synthesis of 4-methoxy-4'-methylbiphenyl (Entry 18) was made using 1\% $(0.10 \mathrm{mmol})$ of Pd@SP-POP2, $50 \mathrm{mmol}$ of 4-bromotoluene, $20 \mathrm{mmol}$ of $\mathrm{Na}_{2} \mathrm{CO}_{3}, 60 \mathrm{mmol}$ of acid 4-methoxyphenylboronic and a solvent mixture of $40 \mathrm{~mL}$ of EtOH and $60 \mathrm{~mL}$ of water. The ${ }^{1} \mathrm{H}-\mathrm{RMN}$ Conversion of the reaction at $80{ }^{\circ} \mathrm{C}$ after $2 \mathrm{~h}$ was $>99 \%$ and the yield of the pure product was of $93 \%$

The second scale-up synthesis of the precursor monomer, 4-4"-dimetoxi-5'-t-butyl-mterphenylene (Entry 22), was made by using 1\% (0.058 mmol) of Pd@SP-POP2, 6 mmol of 1,3- 
dibromo-5-tert-butylbenzene, $24 \mathrm{mmol}$ of $\mathrm{Na}_{2} \mathrm{CO}_{3}, 14 \mathrm{mmol}$ of acid 4-methoxyphenylboronic and a solvent mixture of $35 \mathrm{~mL}$ of EtOH and $24 \mathrm{~mL}$ of water. Because of the high load of compounds in the reaction batch, a combination of ultrasonic ( $25 \%$ of amplitude) and magnetic stirring was employed. ${ }^{1} \mathrm{H}-\mathrm{RMN}$ Conversion of reaction at $80{ }^{\circ} \mathrm{C}$ after $3 \mathrm{~h}$ was of $100 \%$ and the yield of the pure product was of $96 \%$

\subsection{Catalyst recycling in Suzuki-Miyaura coupling}

Recyclability of the heterogeneous catalyst was studied from the Suzuki-Miyaura reaction of 4-bromoanisole with phenylbonic acid (Entry 16). As described in Experimental Section, after each cycle, the catalyst was separated from reaction mixture by centrifugation and washed with EtOH. The first catalytic recycling studies were cumbersome, because a loss of the heterogeneous catalyst after each cycle was observed, which could be due to the loss of very small size porous polymer particles (lower than $100 \mathrm{~nm}$ ) during the catalyst recovery.

It was considered to use magnetic stirring instead of ultrasonic stirring because the latter as a dispersion method of the particles in suspension also produces the breaking down of polymer network aggregates and, consequently, the formation of smaller size particles, which could easily be lost during the separation and washing of catalyst. Interestingly, the use of magnetic stirring brought about a quantitative conversion for the first cycle (>98\%), similar to the value observed when ultrasonic stirring was employed. The conversion was also quantitative for the second cycle. From the third one, a lessening was observed, which was similar to that found for the fourth one.

Therefore, and because the recycling reactions employed a tiny amount of catalyst, the reaction was scale-up to employ 4\% mol of Pd@SP-POP2 catalyst. The results showed that the 
heterogeneous catalyst retained its catalytic activity after five consecutive cycles; the reaction yield was of $95 \%$, as seen in Figure 8.

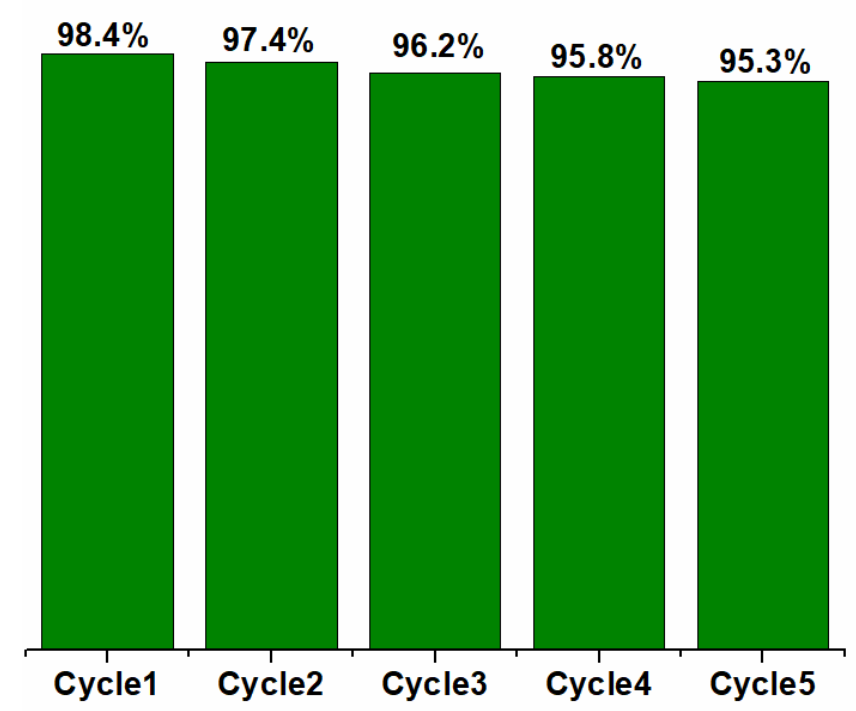

Figure 8. Recyclability of catalyst in the Suzuki-Miyaura reaction. The numbers are the conversion percentage determined by ${ }^{1} \mathrm{H}-\mathrm{RMN}$.

\section{CONCLUSIONS}

New microporous porous organic polymers able to anchor palladium(II)-based catalysts were successfully prepared. Precursor porous organic polymers, POPs, used as catalyst supports were synthesized by a straightforward and high-yield reaction of 1,3,5-triphenylbenzene with ketones activated by electrowithdrawing groups, 4,5-diazafluoren-9-one (DAFO) and 2,3-dioxo-2,3dihydroindole (isatin), in super acidic media using a TFSA/ $\mathrm{CHCl}_{3}$ mixture, in which the strong acid acted as a reaction promoter. These POPs were prepared varying the content of DAFO and isatin in order to modulate the number of bipyridine ligands in the catalyst support. The POPs were characterized employing classical methods of macromolecular chemistry, showing 
astonishing high thermal stability, well above $475{ }^{\circ} \mathrm{C}$, and high char yield. These materials were mainly microporous with BET superficial areas superior to $900 \mathrm{~m}^{2} \mathrm{~g}^{-1}$.

The POP-based Pd(II) catalysts were prepared by simple immersion of the POP in a $\mathrm{Pd}(\mathrm{II})$ acetate solution. These catalysts gave very high yields for Suzuki-Miyaura reaction, no matter the boronic acid or the aryl derivative employed during the synthesis. The cross-coupling compounds could be prepared in a green solvent $\left(\mathrm{EtOH} / \mathrm{H}_{2} \mathrm{O}\right)$, using low loads of metal, and under aerobic conditions. Moreover, these heterogeneous catalysts could easily be recovered from reaction mixture by washing in $\mathrm{EtOH}$ and they could be reused for five consecutive cycles retaining their excellent catalytic activity.

Finally, the synthesis of cross-coupling compounds could easily be scaled-up to give more than $2 \mathrm{~g}$ amounts. In particular, it was feasible to make a bulky monomer precursor having a $\mathrm{m}$ terphenylene moiety, with better yields than those obtained by using a common Suzuki-Miyaura methodology.

\section{ASSOCIATED CONTENT}

(Word Style “TE_Supporting_Information"). Supporting Information. A listing of the contents of each file supplied as Supporting Information should be included. For instructions on what should be included in the Supporting Information as well as how to prepare this material for publications, refer to the journal's Instructions for Authors.

The following files are available free of charge.

brief description (file type, i.e., PDF)

brief description (file type, i.e., PDF) 


\section{AUTHOR INFORMATION}

\section{Corresponding Author}

*(Word Style "FA_Corresponding_Author_Footnote"). * (Word Style

"FA_Corresponding_Author_Footnote"). Give contact information for the author(s) to whom correspondence should be addressed.

\section{Present Addresses}

$\dagger$ If an author's address is different than the one given in the affiliation line, this information may be included here.

\section{Author Contributions}

The manuscript was written through contributions of all authors. All authors have given approval to the final version of the manuscript. $¥$ These authors contributed equally. (match statement to author names with a symbol)

\section{Funding Sources}

Any funds used to support the research of the manuscript should be placed here (per journal style).

\section{Notes}

Any additional relevant notes should be placed here.

\section{ACKNOWLEDGMENT}

(Word Style "TD_Acknowledgments"). Generally the last paragraph of the paper is the place to acknowledge people, organizations, and financing (you may state grant numbers and sponsors here). Follow the journal's guidelines on what to include in the Acknowledgments section. 


\section{ABBREVIATIONS}

CCR2, CC chemokine receptor 2; CCL2, CC chemokine ligand 2; CCR5, CC chemokine receptor 5; TLC, thin layer chromatography.

\section{REFERENCES}

(Word Style "TF_References_Section"). References are placed at the end of the manuscript. Authors are responsible for the accuracy and completeness of all references. Examples of the recommended format for the various reference types can be found at http://pubs.acs.org/page/4authors/index.html. Detailed information on reference style can be found in The ACS Style Guide, available from Oxford Press.

BRIEFS (Word Style "BH_Briefs"). If you are submitting your paper to a journal that requires a brief, provide a one-sentence synopsis for inclusion in the Table of Contents.

SYNOPSIS (Word Style "SN_Synopsis_TOC”). If you are submitting your paper to a journal that requires a synopsis, see the journal's Instructions for Authors for details. 